Radio Waves in the lonosphere

The Mathematical Theory of the Reflection of Radio Waves from Stratified. Ionised Layers. By Dr. K. G. Budden. Pp. xxiv +542. (Cambridge: At the University Press, 1961.) 95s. not.

【NTIL recently, practically all our knowledge of the ionized regions of the terrestrial upper atmosphere was obtained from ground-based radio soundings experiments. In such investigations a full understanding of the propagation of electromagnetic waves in an ionized medium is clearly essential.

The basic theory of radio-wave propagation in the ionosphere was originally given by Sir Edward Appleton, and in the thirty years since its publication the 'magneto-ionic theory' has been extensively developed to cover all aspects of such propagation. Dr. Budden has himself made substantial contributions to the mathematical theory of ionospheric radiowave propagation and the publication of this authoritative work is indeed to be welcomed. The book is based on a course of lectures given annually at Cambridge, and in the preface the author emphasizes that the stress throughout is on the understanding of the mathematical methods rather than on immediate practical problems, and rightly adds that "the radio engineer who really understands the mathematies is much better equipped to solve practical problems than one who does not".

The volume consists of some twenty-three chapters and covers the whole subject in great detail. Topics discussed include the derivation of the basic equa tions, propagation in isotropic and anisotropic media, the properties of the Appleton-Hartree formula, reflexion at boundaries of slab and slowly varying media, the W.K.B. solutions, vertical and oblique incidence propagation, ray tracing, coupled waveequations, full-wave solutions and reciprocity. A number of interesting examples, many taken from Cambridge Tripos examinations, are ineluded in the volume. The volume is well indexed and a selected bibliography of nearly three hundred of the more important original papers is included.

Recently, Mr. J. A. Ratcliffe, a former colleague of Dr. Budden, published a volume on "The Magnetoionic Theory" which gave the basic physical principles of the subject. This more extensive volume covers the full mathematical theory and is complementary to that of Mr. Ratcliffe. Taken together the two volumes form the most complete treatises yet published on radio-wave propagation in an ionized medium.

W. J. G. BeynoN

\section{Annual Review of Nuclear Science}

Vol. 10. Edited by Emilio Segrè, in association with Gerhart Friedlander and Walter E. Meyerhof. Pp. vii +617 . (Palo Alto, Calif.: Annual Reviews, Inc., 1960.) 7 dollars.

THIS is the tenth volume to appear in this admirable series, and the quality of the review articles remains very high. Very few of the exciting advances of nuclear, high-energy or radiobiological physics have been neglected in the ten volumes so far issued. In this one, low-energy physics is represented by articles on the neutrino, on heavy-ion interactions and on internal conversion. For the high-energy physicist there is an article on the large bubble chambers and a particularly useful article on the opties of high-energy beams. Two reviews are concerned with nuclear recoils. One describes how they are now used as a tool for analysis of reaction and fission studies. The other shows how organic compounds may be labelled via the recoil. Activation, separation and chemical attachment can be arranged to occur all in one step. There is an interesting approach to the theory of energy-levels of light nuclei by Talmi and Unna in which a semi-empirical modification of the shell model seems to give remarkable agreement with experiment. Two papers on cosmic rays, one on air showers and the other on results gained during the International Geophysical Year, show that this subject is still very much alive, having received a fresh impetus from satellite data. A technological application of nuclear physics is reviewed in an article on subsurface prospecting. The application of such techniques to oil prospecting has received much attention. Finally, the usual reviews of radiobiology are this year concerned with two subjects of great topical importance. One is the metabolism of radioactive emitters which get inside the human body; the other is concerned with the long-term effects of radiation on the human organism. This latest volume of the Annual Reviews will be of great interest to most nuclear physicists.

E. B. Paul

\section{Laënnec: His Life and Times}

By Dr. Roger Kervran. Translated from the French by D. C. Abrahams-Curiel. Pp. $x+213$. (London and New York: Pergamon Press, 1960.) 21s. net.

CARLYLE defined history as "the essence of innumerable biographies". It is, indeed, the story of the lives and works of great men and women.

René Théodore Hyacinthe Laënnec (1781-1826) well deserves to be remembered, and not merely as the inventor of the stethoscope (1816) and the author of that classic treatise, "Traité de l'Auscultation Médiate" (1819), which described the phonomena revealed by the new instrument. Besides being a great physician, Laënnec was a poet and patriot who rendered valuable service to his native Brittany by his studies of its language, literature and folk-lore. During his lamentably brief career he accomplished much, and he died at the age of forty-five, a victim, like his colleagues Bayle and Bichat, of pulmonary tuberculosis, the disease he had striven so hard to elucidate.

The life-story of Laënnec has often been told, but never with such sympathetic insight as that possessed by his fellow-Breton, Dr. Roger Kervran, who has allowed his hero to speak for himself so far as possible by quoting from many of his letters and other writings. It is a picture of the young physician struggling against a background of revolutionary wars, family troubles, lawsuits and professional jealousy: a sad life, and yet, despite its troubles and its brevity, a life of great accomplishment.

Although the scene of his medical work was Paris, his thoughts were ever with his beloved Brittany, where his memory has been honoured by a fine bronze statue in the public square at Quimper.

The sub-headings in each of the ten chapters of the book are mostly single words, such as studies, medicine, work, activities, etc., and the reader may find them distracting rather than informative. A much more serious defect is the absence of an index, so essential to every biography. A portrait of Laënnec, and an outline map of Brittany, would have added to the interest.

Nevertheless, this new approach to Laënnec makes it a unique study. Dougras Guthrie 